Open Access

\title{
Fanconi anemia cells with unrepaired DNA damage activate components of the checkpoint recovery process
}

\author{
Alfredo Rodríguez ${ }^{1,2}$, Leda Torres', Ulises Juárez' , David Sosa', Eugenio Azpeitia ${ }^{3,4,5}$, \\ Benilde García-de Teresa ${ }^{1}$, Edith Cortés ${ }^{6}$, Rocío Ortíz ${ }^{6}$, Ana M. Salazar ${ }^{7}$, Patricia Ostrosky-Wegman ${ }^{7}$, \\ Luis Mendoza ${ }^{4,7}$ (10 ${ }^{\dagger}$ and Sara Frías ${ }^{1,7^{*}+}$
}

*Correspondence:
sarafrias@biomedicas.unam.mx
${ }^{\dagger}$ Equal contributors
${ }^{1}$ Laboratorio de Citogenética,
Departamento de Investigación en
Genética Humana, Instituto
Nacional de Pediatría, D.F., México
7 Instituto de Investigaciones
Biomédicas, Universidad Nacional
Autónoma de México, D.F., México
Full list of author information is
available at the end of the article

\begin{abstract}
Background: The FA/BRCA pathway repairs DNA interstrand crosslinks. Mutations in this pathway cause Fanconi anemia (FA), a chromosome instability syndrome with bone marrow failure and cancer predisposition. Upon DNA damage, normal and FA cells inhibit the cell cycle progression, until the G2/M checkpoint is turned off by the checkpoint recovery, which becomes activated when the DNA damage has been repaired. Interestingly, highly damaged FA cells seem to override the G2/M checkpoint. In this study we explored with a Boolean network model and key experiments whether checkpoint recovery activation occurs in FA cells with extensive unrepaired DNA damage.

Methods: We performed synchronous/asynchronous simulations of the FA/BRCA pathway Boolean network model. FA-A and normal lymphoblastoid cell lines were used to study checkpoint and checkpoint recovery activation after DNA damage induction. The experimental approach included flow cytometry cell cycle analysis, cell division tracking, chromosome aberration analysis and gene expression analysis through qRT-PCR and western blot.
\end{abstract}

Results: Computational simulations suggested that in FA mutants checkpoint recovery activity inhibits the checkpoint components despite unrepaired DNA damage, a behavior that we did not observed in wild-type simulations. This result implies that FA cells would eventually reenter the cell cycle after a DNA damage induced G2/M checkpoint arrest, but before the damage has been fixed. We observed that FA-A cells activate the G2/M checkpoint and arrest in G2 phase, but eventually reach mitosis and divide with unrepaired DNA damage, thus resolving the initial checkpoint arrest. Based on our model result we look for ectopic activity of checkpoint recovery components. We found that checkpoint recovery components, such as PLK1, are expressed to a similar extent as normal undamaged cells do, even though FA-A cells harbor highly damaged DNA.

Conclusions: Our results show that FA cells, despite extensive DNA damage, do not loss the capacity to express the transcriptional and protein components of checkpoint recovery that might eventually allow their division with unrepaired DNA damage. This might allow cell survival but increases the genomic instability inherent to FA individuals and promotes cancer.

Keywords: DNA damage, Checkpoint recovery, Boolean network model 


\section{Introduction}

The molecular basis of the DNA damage response (DDR) has been largely elucidated through the study of the rare chromosome instability syndromes (CIS) [1] which are cytogenetically characterized by the spontaneous appearance of chromosome aberrations (CA) as well as hypersensitivity to specific DNA damaging agents [2-4]. The best-known CIS include Bloom syndrome (BS) which appears due to mutations in BLM helicase $[5,6]$ and results in increased sister chromatid exchanges [7], Ataxia Telangiectasia (AT) that shows particular clonal chromosome rearrangements as a consequence of mutations in the checkpoint kinase ATM gene[8-11], and Fanconi anemia (FA) [12] whose phenotype results from mutations in any of the genes that conform the FA/BRCA pathway [13-19] and consists of chromatidic breaks, iso-chromatidic breaks and radial exchange figures among chromosomes. Even if these breaks and radials are predominantly seen in FA, they can also be observed in BS and AT [4, 20]. Although patients affected by CIS display phenotypic similarities, such as growth defects, compromised immunological system and an increased risk to develop cancer $[1,20]$, each syndrome presents particular phenotypes and pivotal data. Namely, BS shows sun sensitivity [5], AT presents progressive cerebellar ataxia and oculo-cutaneous telangiectases [8], while FA is characterized by congenital malformations and progressive bone marrow failure [21]. The products of these genes interact in the cell's DNA damage response [1], and thus the deficiency of any of these proteins diminishes the efficiency of a cell to cope with DNA damage, leading to their accumulation.

Given the critical role that these proteins have in the protection of the human genome, certain authors have speculated that survival of CIS patients is an oddity and that cells escaping apoptotic death do so by constitutively inducing alternative replication or DNA damage tolerance pathways, which might contribute to the characteristic mutator phenotypes observed in the CIS [22].

In the particular case of FA, cells are hypersensitive to agents that create DNA interstrand crosslinks (ICL), such as mitomycin C (MMC) or diepoxybutane (DEB) [21]. The treatment of FA cells with MMC or DEB induces a blockage during the G2 phase of the cell cycle and exacerbates the frequency of CAs, including double strand breaks (DSBs) and radial exchange figures [23]. Biallelic mutations in at least one of 18 distinct FANC genes can generate FA. The products of these genes interact in the so-called Fanconi Anemia/Breast Cancer (FA/BRCA) pathway [13-18], involved in the repair of the DNA damage generated by intrinsic acetaldehydes and extrinsic ICL inducing agents. Therefore, a deficiency in this pathway results in DNA damage accumulation that might originate congenital malformations, uncontrolled hematopoietic cell death and cancer in FA patients [24-27].

Over the years, the FA diagnosis assays and experimental approaches have shown that a great proportion of FA cells succumb to DNA damage due to their inherent repair deficiencies. However, some cells are able to tolerate high levels of DNA damage and progress into mitosis despite a great amount of CAs. The mechanisms that allow the cells with CAs to omit the DNA damage integrity checkpoints remain uncertain because the more obvious candidate, the G2/M checkpoint, is considered to be properly activated in FA cells [28-30]. Thus, the idea of a malfunctioning checkpoint in FA cells has been ruled out and it is presumed that some other mechanisms are responsible for the checkpoint override in FA cells with unrepaired DSBs. 
In recent times, an attenuated G2 checkpoint phenotype, characterized by low levels of CHK1 (NP_001107594.1) and p53 (NP_000537.3), absence of the G2 phase arrest, and arrival to metaphase with a large number of $M M C$-induced CAs has been described in cells from adult FA individuals [31]. It has been suggested that the G2 checkpoint attenuation could be an important contributor for the increased life expectancy of these FA patients, and that the release of cells with unrepaired DSBs could promote neoplastic transformation [31]. Nevertheless, since non-attenuated FA cells carrying unrepaired DNA damage achieve a correct G2/M checkpoint activation [28-30], the aforementioned mechanism seems to be a particular scenario rather than a general mechanism to enable the resolution of the $\mathrm{G} 2$ checkpoint blockage.

Network modeling has been previously used with success to study the dynamics of biological systems [32-37]. Particularly, we developed a Boolean network model (BNM) for the FA/BRCA pathway [38], in which we observed that the inclusion of the checkpoint recovery (CHKREC) node is crucial for the network correct function. In our model, the CHKREC node represents the process that relieves the inhibition of the checkpoint machinery over the mitosis-promoting factor (Cyclin B/CDK1) after a complete DNA damage repair to allow further cell division [39-42]. This node comprises the G2 transcriptional program that activates the expression of genes driving the G2/M transition and the protein program that inactivates the $\gamma \mathrm{H} 2 \mathrm{AX}$ histone (NP_002096.1) and checkpoint kinases [43]. We presumed that CHKREC activation might be releasing cells with unrepaired DNA damage in FA mutants. To test this possibility, as well as to validate the inclusion of the node itself in the FA/BRCA network, we used a simplified version of our previously published FA/BRCA pathway BNM and experimentally determined if CHKREC components become activated in FA cells during G2/M during MMC-induced arrest.

\section{Materials and methods}

\section{Model and simulations}

The simplification of the FA/BRCA network was done by reorganizing the existing 28 nodes and 122 interactions [38], resulting in a deterministic BNM with 15 nodes and 66 interactions (Fig.1 and Table 1) that vastly simplifies the computational analysis while maintaining the qualitative dynamical behavior of the original FA/BRCA network. The simplification was made by collapsing the network components that share functions or belong to a single pathway into one single node. We were careful to preserve all the important functional categories of the network and made sure to recover the behavior of the wild type and mutant networks. The modifications and simplification criteria are listed in Table 2.

Simulations were performed for the wild type and all possible gain of function or null mutants of the model with synchronous and asynchronous update regimes. Here we report the simulations exploring checkpoint and CHKREC function in wild type and FA core mutants. These null mutants were simulated fixing to zero the node of interest.

In these mutants we simulated the response to ICLs, whose presence is dependent on the time that the system requires to turn it off. With our model we simulated two biologically relevant conditions, a short exposure to ICLs, which is supposed to be repaired fast and efficiently by the FA/BRCA pathway (Fig. 2b) and a persistent exposure to damaging agents, which is more difficult to face given the accumulation of damage and saturation 


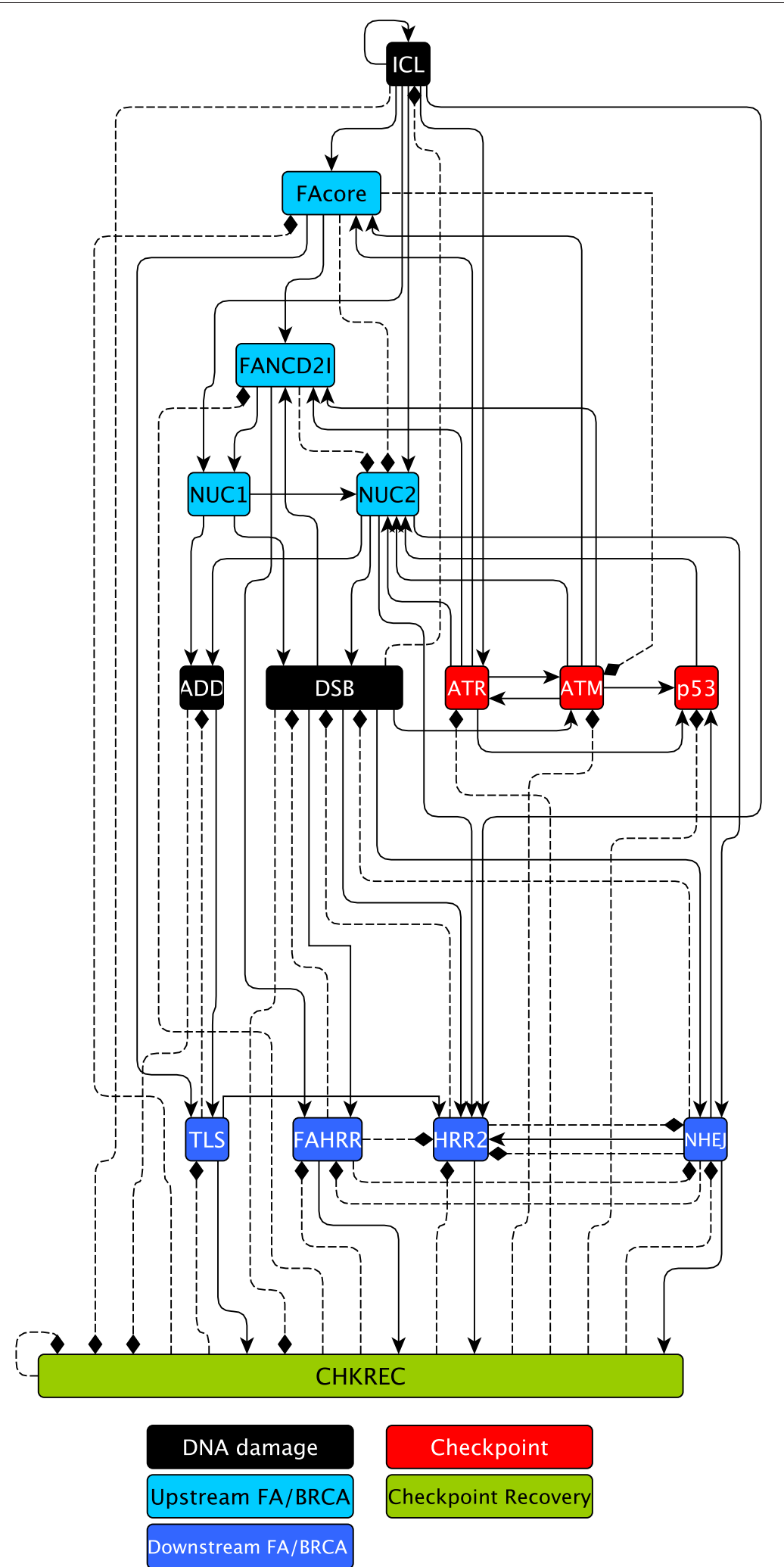

Fig. 1 (See legend on next page) 
(See figure on previous page)

The latest FA/BRCA network. In response to an ICL, the FA/BRCA network responds by blocking the cell cycle through the ATR and ATM checkpoint kinases and their downstream target p53. Similarly, the FA core complex (FAcore) becomes activated and ubiquitinates FANCD2I complex, which in turn recruits DNA endonucleases (NUC1 and NUC2). These endonucleases unhook the ICL generating a DNA adduct (ADD) and a double strand break (DSB). Translesion synythesis (TLS) takes over the ADD while the DSB can be rejoined either by FA/BRCA-dependent Homologous Recombination (FAHRR), FA/BRCA-independent Homologous Recombination (HRR2), or by the error prone Non-Homologous End-Joining (NHEJ) pathways. Finally, we predict that the CHKREC node, composed by the G2/M transcriptional program and checkpoint recovery proteins, turns off the checkpoint and DNA repair proteins. Rectangles represent proteins or protein complexes, pointed arrows are positive regulatory interactions, and dashed lines with blunt arrows are negative regulatory interactions. Readers may refer to [38] for a more detailed description of the FA/BRCA pathway

of the DNA repair pathway (Fig. 2c). The response to short ICL exposure was simulated in both the wild type (Fig. 2b) and FAcore mutant (Fig. 2d) with the ICL value ON only at the starting time step; whereas a continuous exposure to DNA damage was simulated fixing the ICL value to 1 during the entire simulation. We performed exhaustive searches of all possible trajectories and attractors in the system.

\section{Implementation}

The current FA/BRCA network is available through the supplementary file FAnetwork.r this file has been tested using R (v3.1.1) package BoolNet (v1.63) [66]. Additionally, the SBML-qual implementation of the model obtained by using the toSBML() function of BoolNet is provided as the supplementary file FAnetwork.sbml. The generated file was validated using the online service at http://sbml.org/Facilities/Validator/.

Table 1 Boolean functions for the nodes in the FA/BRCA network

\begin{tabular}{|c|c|}
\hline RULES & REFERENCES \\
\hline$\overline{\mathrm{ICL}} \leftarrow \mathrm{ICL} \wedge \neg \mathrm{DSB}$ & [38] \\
\hline FAcore $\leftarrow I C L \wedge(A T R \vee A T M) \wedge \neg$ CHKREC & {$[14,16,44-46]$} \\
\hline $\begin{aligned} & \text { FANCD2I } \leftarrow \text { FAcore } \wedge((\text { ATR } \vee \text { ATM }) \vee((A T R \vee A T M) \wedge D S B)) \wedge \\
& \neg(\text { CHKREC })\end{aligned}$ & [47-49] \\
\hline $\mathrm{NUC1} \leftarrow \mathrm{ICL} \wedge \mathrm{FANCD} 2 \mathrm{I}$ & {$[50] ;[38]$} \\
\hline $\begin{aligned} \mathrm{NUC2} \leftarrow & (\mathrm{ICL} \wedge(\text { ATR } \vee \text { ATM }) \wedge \neg(\text { FAcore } \wedge \text { FANCD2I) }) \vee \\
& (\mathrm{ICL} \wedge \mathrm{NUC1} \wedge \mathrm{p} 53 \wedge \neg(\text { FAcore } \wedge \text { FANCD2I) })\end{aligned}$ & [51]; [38] \\
\hline $\mathrm{ADD} \leftarrow(\mathrm{NUC1} \vee \mathrm{NUC2} \vee(\mathrm{NUC1} \wedge \mathrm{NUC2})) \wedge \neg(\mathrm{TLS})$ & {$[47,50,51]$} \\
\hline $\mathrm{DSB} \leftarrow(\mathrm{NUC1} \vee \mathrm{NUC2}) \wedge \neg(\mathrm{NHEJ} \vee \mathrm{FAHRR} \vee \mathrm{HRR} 2)$ & {$[50,52]$} \\
\hline $\mathrm{TLS} \leftarrow(\mathrm{ADD} \vee(\mathrm{ADD} \wedge \mathrm{FAcore})) \wedge \neg(\mathrm{CHKREC})$ & {$[53,54]$} \\
\hline $\mathrm{FAHRR} \leftarrow \mathrm{DSB} \wedge \mathrm{FANCD} 2 \mathrm{I} \wedge \neg(\mathrm{NHEJ} \wedge \mathrm{CHKREC})$ & {$[53,54]$} \\
\hline $\begin{aligned} \mathrm{HRR} 2 \leftarrow & (\mathrm{DSB} \wedge \mathrm{NUC2} \wedge \mathrm{NHEJ} \wedge \mathrm{ICL} \wedge \neg(\mathrm{FAHRR} \vee \mathrm{CHKREC})) \vee \\
& (\mathrm{DSB} \wedge \mathrm{NUC2} \wedge \mathrm{TLS} \wedge \neg(\mathrm{NHEJ} \vee \mathrm{FAHRR} \vee C H K R E C))\end{aligned}$ & [38] \\
\hline $\mathrm{NHEJ} \leftarrow(\mathrm{DSB} \wedge \mathrm{NUC2} \wedge \neg($ FAHRR $\vee \mathrm{HRR} 2 \vee \mathrm{CHKREC}))$ & {$[49,52,55-57]$} \\
\hline ATR $\leftarrow(I C L \vee A T M) \wedge \neg$ CHKREC & {$[58-60]$} \\
\hline ATM $\leftarrow($ ATR $\vee D S B) \wedge \neg$ CHKREC $\vee$ FAcore & {$[61,62]$} \\
\hline P53 $\leftarrow(($ ATR $\vee A T M) \vee N H E J) \wedge \neg$ CHKREC & {$[58,63,64]$} \\
\hline $\mathrm{CHKREC} \leftarrow((T L S \vee N H E J \vee F A H R R \vee H R R 2) \wedge \neg D S B) \vee$ & {$[52,53]$} \\
\hline$((\neg \mathrm{ADD}) \wedge(\neg \mathrm{ICL}) \wedge(\neg \mathrm{DSB}) \wedge \neg(\mathrm{CHKREC}))$ & {$[38,65]$} \\
\hline
\end{tabular}

Key references are included. Full discussion of interactions can be found in [38] 
Table 2 Network model simplification criteria

\begin{tabular}{|c|c|c|}
\hline $\begin{array}{l}\text { Node in the } \\
\text { original BNM }\end{array}$ & $\begin{array}{l}\text { Nodes in the } \\
\text { simplified BNM }\end{array}$ & Simplification criteria \\
\hline $\mathrm{ICL}$ & $\mathrm{ICL}$ & Unchanged node \\
\hline FANCM, FAcore & FAcore & $\begin{array}{l}\text { ICL recognition proteins working } \\
\text { together in the upstream FA/BRCA } \\
\text { pathway }\end{array}$ \\
\hline FANCD2I & FANCD2I & Unchanged node \\
\hline MUS81 & NUC1 & $\begin{array}{l}\text { Nuclease mediated } \\
\mathrm{ICL} \text { incision }\end{array}$ \\
\hline XPF, FAN1 & NUC2 & $\begin{array}{l}\text { Nuclease mediated } \\
\text { ICL incision }\end{array}$ \\
\hline ADD & ADD & Unchanged node \\
\hline DSB & DSB & Unchanged node \\
\hline ATR, CHK1, H2AX & ATR & $\begin{array}{l}\text { These proteins act in the } \\
\text { Checkpoint pathway }\end{array}$ \\
\hline ATM, CHK2, H2AX & ATM & $\begin{array}{l}\text { These proteins act in the } \\
\text { Checkpoint pathway }\end{array}$ \\
\hline p53 & p53 & Unchanged node \\
\hline PCNATLS & TLS & This is only a change in name \\
\hline $\begin{array}{l}\text { FANCJMLH1, MRN, BRCA1, } \\
\text { FANCD1N, RAD51, HRR, } \\
\text { sSDNARPA }\end{array}$ & FAHRR & $\begin{array}{l}\text { These proteins act in the } \\
\text { Homologous Recombination } \\
\text { Repair pathway }\end{array}$ \\
\hline - - & HRR2 & $\begin{array}{l}\text { New node representing the } \\
\text { alternative Homologous } \\
\text { Recombination Repair Pathway }\end{array}$ \\
\hline KU, DNAPK, NHEJ & NHEJ & $\begin{array}{l}\text { These proteins act in the } \\
\text { Non-Homologous End-Joining } \\
\text { DNA repair pathway }\end{array}$ \\
\hline USP1, CHKREC & CHKREC & $\begin{array}{l}\text { Global negative regulators } \\
\text { of the FA/BRCA pathway }\end{array}$ \\
\hline
\end{tabular}

\section{Cell culture and treatments}

Lymphoblastoid cell lines from FA-A VU817 (kindly donated by Dr. Hans Joenje, VU University Medical Center) and normal NL-49 (generated in our institution under written informed consent) were maintained in RPMI 1640 medium supplemented with $10 \%$ fetal calf serum, $1 \%$ non-essential aminoacids and $1 \%$ sodium pyruvate (all from GIBCO, Waltham, Massachusetts, USA). During experiments 300,000 cell/ml were exposed to 10 $\mathrm{ng} / \mathrm{ml}$ of MMC (Sigma-Aldrich Co, St. Louis MO, USA) for $24 \mathrm{~h}$ and harvested to evaluate different markers. All the experiments were run by triplicate.

\section{Chromosome aberration and nuclear division index analysis}

For chromosome aberration analysis, colchicine (Sigma-Aldrich Co, St. Louis MO, USA) (final concentration of $0.1 \mu \mathrm{g} / \mathrm{ml}$ ) was added to cell cultures one hour before harvesting with the conventional method. Twenty five metaphases per experimental condition were scored by recording the number of chromatid breaks, chromosome breaks and radial figures. A cytokinesis block assay, using $3 \mu \mathrm{g} / \mathrm{ml}$ of cytochalasin B (Sigma-Aldrich Co, St. Louis MO, USA), was implemented to obtain binucleated and tetranucleated cells: after exposing the cells to MMC for $24 \mathrm{~h}$, they were washed, reincubated with fresh 


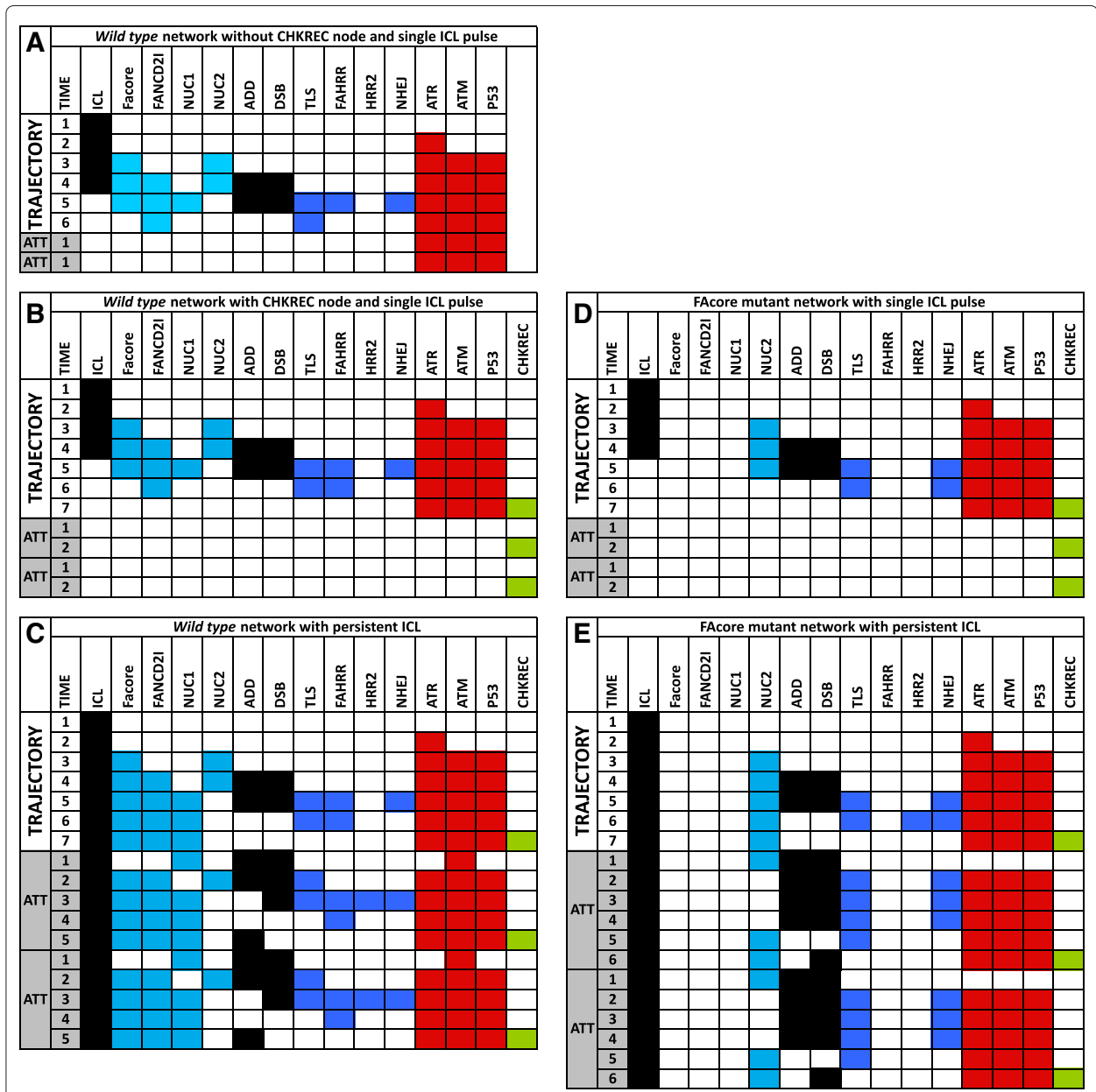

Fig. 2 FA network simulations. a The current information regarding the FA/BRCA pathway have not uncovered the mechanism that allows the resolution of the G2/M checkpoint after DNA damage and further cell division. b Trajectories and attractor of the wild type FA/BRCA network under an ICL pulse. In this simulation wild type cells repair DNA damage through the FA/BRCA pathway and arrive to CCP attractor after activating the CHKREC node once the damage has been fixed. The inclusion of the CHKREC node, as a checkpoint negative regulator, allows to explore the mechanisms behind cell division after checkpoint resolution. $\mathbf{c}$ In response to a continuous ICL DNA damage, wild type cells arrive to a CCA attractor with activation of the checkpoint and DNA damage repair nodes, the CHKREC node becomes eventually activated in this attractor. $\mathbf{d}$ Under and ICL pulse FAcore mutant cells activate the NHEJ pathway to repair DNA damage and arrive to a CCP attractor. e In response to a continuous ICL DNA damage, FAcore mutant cells concomitantly activate the checkpoint and the CHKREC nodes. Node names are indicated at the topmost row. The leftmost column indicates simulation time steps in arbitrary units. Time steps corresponding to trajectories are indicated and time steps corresponding to attractors are indicated by shaded gray and "ATT". For illustrative purpose cyclic attractors are represented twice

cytochalasin B for another $24 \mathrm{~h}$ and harvested using a 7:1 methanol:acetic acid fixative. Five hundred cells were scored to quantify the number of micronuclei, mononucleated, binucleated and tetranucleated cells in every experimental condition [67].

\section{Flow cytometry analysis}

To determine cell cycle distribution and mitotic index the cells were fixed with $70 \%$ ice-cold ethanol, washed twice with PBS (GIBCO, Waltham, Massachusetts, USA) and permeabilized with $0.1 \%$ PBS $1 \mathrm{X}+$ Triton X100. The MPM2 antibody (CellSignaling, 
Boston MA, USA) was used to determine the number of cells in M phase. The antibody was marked with the labeling anti-mouse Alexa-Fluor 488 fluorophore from the Zenon Tricolor Mouse IgG Labeling Kit \# 1 (Invitrogen, Carlsbad, CA, USA) according to manufacturer instructions. The cells were incubated during $1 \mathrm{~h}$ with the antibody, washed with PBS/NGS $10 \%$ and counterstained with propidium iodide (Sigma-Aldrich Co, St. Louis MO, USA). A total of 20,000 events were scored in a FACSCan (Beckton Dickinson, Ontario, CA) cytometer and the analysis was performed using the CellQuest program version 3.2.1.

\section{RNA extraction and quantitative real-time PCR (qRT-PCR)}

Total RNA was obtained employing the combined method of TRIzol (Invitrogen, Carlsbad, CA, USA) followed by RNeasy mini procedure (Qiagen, Valencia, CA, USA), according to manufacturer instructions. Before retro-transcription, $1 \mu \mathrm{g}$ of total RNA was treated with $0.1 \mathrm{U}$ RNase-free DNase I (Invitrogen, Carlsbad, CA, USA) in 20 $\mathrm{mM}$ Tris- $\mathrm{HCl}, \mathrm{pH} 8.3,50 \mathrm{mM} \mathrm{KCl}$, and $1 \mathrm{mM} \mathrm{MgCl} 2$ for $15 \mathrm{~min}$ at room temperature. The enzyme was inactivated by adding EDTA to a final concentration of $1 \mathrm{mM}$ followed by incubation at $65^{\circ} \mathrm{C} / 10 \mathrm{~min}$. Total RNA was retro-transcribed into cDNA using the Transcriptor First Strand cDNA Synthesis Kit (Roche Diagnostics, GmbH, Mannheim, Germany) using anchored-oligo (dT) 18 primer (50-pmol/ $\mu \mathrm{L}$ ) and Random hexamer primer $(600 \mathrm{pmol} / \mu \mathrm{L})$, protector RNase Inhibitor $(20 \mathrm{U})$, and Transcriptor Reverse Transcriptase (10 U). Total RNA and cDNA were quantified using a Nanodrop ND 1000 spectrophotometer (Nanodrop Technologies, Wilmington, DE, USA). Real-time quantitative-PCR (qRT-PCR) was performed by duplicate for each cell line, treatment and biological repeat using $2 \mu \mathrm{g}$ of cDNA per reaction with the Universal Probes system (Roche Diagnostics, GmbH, Mannheim, Germany) and the Light Cycler Taq Man Master kit (Roche Diagnostics, GmbH, Mannheim, Germany). 7SL (NR_002715.1), $\beta 2$ microglobulin (NM_004048.2) and $\beta$-actin (NM_001017992.3) gene expression were used as reference. Primers for each gene were designed on-line with the ProbeFinder Software (http://www.universalprobelibrary.com) and manufactured by the Sequencing and Synthesis Unit (IBT, UNAM). The qRT -PCR was carried out in a Light Cycler 2.0 Carousel Roche equipment.

\section{Protein extraction and immunoblot}

Cells were harvested in TLB lysis buffer supplemented with the Complete C protease and phosphatase inhibitors mix (Roche, Mannheim, Germany). Quantification was made with Bradford ready to use reagent (Biorad, Hercules, CA). Total cell protein $(10 \mu \mathrm{g})$ was separated by $12 \%$ SDS- PAGE, transferred to nitrocellulose membrane (Biorad, Hercules, $\mathrm{CA}$ ) and incubated with primary antibodies overnight at $4^{\circ} \mathrm{C}$ followed by incubation with goat-anti-mouse (Invitrogen, Carlsbad, CA, USA) or goat-anti-rabbit (Invitrogen, Carlsbad, CA, USA) HRP tagged secondary antibodies. Bands were visualized with Lumigen on Amersham Hyperfilm (GE Healthcare, Fairfield, CT, USA). Primary antibodies used are listed below: anti-WEE1 (NP_001137448.1) (Abcam, Cambridge, UK), anti-WIP1 (NP_003611.1 ) (Abcam, Cambridge, UK), anti-pCHK1 Ser345 (Cell Signaling, Boston MA, USA), anti- $\gamma$ H2AX (Genetex, Irvine, CA), anti-p21 (NP_000380.1) (Genetex, Irvine, CA), anti-MYT1 (NP_004526.1) (Genetex, Irvine, CA), anti-Aurora A (NP_003591.2) (Abcam, Cambridge, UK), anti-CDC25B (NP_001274445.1) (Genetex, Irvine, CA) and 
anti-PLK1 (NP_005021.2) (Abcam, Cambridge, UK); anti-GAPDH (NP_001243728.1) was used as loading control (Genetex, Irvine, CA).

\section{Statistical analysis}

Experimental groups were compared using two way ANOVA, followed by Tukey's posthoc test. A difference was considered significant if $p<0.05$.

\section{Results}

FA/BRCA network analyses show that CHKREC promotes cell division in FA mutants with DNA damage

Appropriate function of the FA/BRCA pathway guarantees the complete repair of ICLs and correct checkpoint activation impedes cell division upon DNA damage detection [68]. Therefore an accurate model of the FA/BRCA pathway should show cell division after complete DNA damage repair in wild-type cells. In our previous work [38], we demonstrated that the inclusion of the CHKREC node is crucial to reproduce correctly the DNA repair behavior. Without CHKREC, as a negative regulator of the checkpoint nodes, the network remains in a permanent arrest after DNA repair (Fig. 2a). Hence, CHKREC provides a mechanism that allows the cell to resolve the checkpoint (Fig. 2b).

We performed synchronous and asynchronous simulations with the updated and simplified version of the FA/BRCA network and observed that the simplified model is able to reproduce all the previously reported results (Fig. $2 \mathrm{~b}$ and data not shown). Only synchronous simulations are shown given that asynchronous update results in complex trajectories, while preserving the attractors of the original model [38]. Hence, we decided to use our new version of the network model to deeply study the role of CHKREC in the abnormal behavior of FA cells.

Ninety percent of FA patients carry mutations in one of the components of the FA core complex, including FANCA (NP_000126.2), FANCB (NP_001018123.1), FANCC (NP_000127.2), FANCE (NP_068741.1), FANCF (NP_073562.1), FANCG (NP_004620.1), FANCL (NP_001108108.1) and FANCM (NP_001295063.1) [21]. Hence, to study the role of CHKREC in FA cells, we simulated the FA core complex mutant, represented in our model by the FA core node, and compared its dynamic behavior to a wild type network.

Our simulations recapitulate two cellular behaviors relevant to DNA damage that are represented by two specific attractors. We denominated them as the cell cycle progression attractor (CCP), and the cell cycle arrest attractor (CCA). The CCP attractor is characterized by the CHKREC-mediated inactivation of every checkpoint node, namely ATM, ATR and p53, followed by CHKREC oscillations. It has been experimentally proven that CHKREC is required for the activation of the genes and proteins that release the G2/M checkpoint to allow cell cycle progression [39, 41-43]. Hence, the cyclic behavior of the CHKREC node in the CCP attractor represents the periodical transition into the cell cycle, and should ideally be reached when DNA damage has been repaired. In our simulations both wild type and FA core mutant reach the CCP attractor after an ICL pulse of damage (Fig. 2b,d).

On the other hand, CCA is a cyclic attractor that represents a checkpoint mediated cell cycle arrest that is reached when DNA damage persists and the cell is engaged in a DNA repair process. Once the system has reached CCA there is recurrent activation of the DNA damage repair and the checkpoint nodes, accompanied by CHKREC node 
activation, thus CHKREC activation might occur during an ongoing CCA but the cell would not divide unless the checkpoint nodes are turned off, which in turn would not occur until the DNA damage has been completely removed. Although more than one combination of node activation patterns can be interpreted as a CCA attractor, all such patterns share the activation of the DNA damage and the checkpoint nodes followed by activation of CHKREC.

In our simulations with a constant ICL damage the wild type (Fig. 2c) and FA core mutant (Fig. 2e) networks reach a CCA attractor with checkpoint and CHKREC activation. In the wild-type simulation we observe that the checkpoint components are never completely down-regulated in presence of DSBs or during the ICL stimulus, however the FA core mutants have a transient state in which DSBs are activated and the checkpoint components are inactivated, as a response to CHKREC activation in the previous step. This result suggests that FA cells might overcome, through CHKREC activation, the cell cycle arrest despite unrepaired DNA damage.

Our modeling approach has advanced many interesting predictions about the effect of FA mutations during the DNA repair process. In the next section we focused on the one that we considered more general and important. Namely, that CHKREC inhibition over the checkpoint components might allow the division of FA cells even if DNA has not been completely repaired. Hence, we verified if CHKREC activation might occur in FA cells after DNA damage induction allowing their eventual cell division, even in the presence of unrepaired DNA damage.

\section{CHKREC components are activated in FA cells with unrepaired DNA damage}

Cells should divide only after successful and thorough DNA repair $[68,69]$, which is achieved through efficient DNA repair and accurate G2/M checkpoint activation. FA core mutants are DNA repair deficient but G2/M checkpoint proficient, therefore the fact that they are able to divide despite a strong G2/M checkpoint activation and carrying unrepaired DNA damage is remarkable. Our BNM anticipates that turning off a DNA damage-induced G2/M checkpoint might occur through CHKREC activation, thus allowing cell division. We verified this prediction by following the transit through $\mathrm{G} 2$ and $\mathrm{M}$ phases in the presence of DNA damage in wild type (NL49) and FA-A (VU817) cell lines exposed to MMC.

First, we evaluated checkpoint activation using several markers. Using PI cell cycle flow cytometry analysis we observed that treatment with MMC induces an over time increase in the number of FA-A cells arrested in G2 when compared to normal cells (Fig. 3a, left panel), as well as a reduction in the number of mitotic cells (MPM2+ cells in Fig. 3a, right panel), accompanied by a lag of approximately $6-12$ hours in the peak of MPM2+ cells in both MMC-treated FA and normal cells, compared to their respective untreated controls (see 24 and 30 hrs of MMC treatment). However normal MMC treated cells have the highest peak as they deliver a bigger number of cells into $\mathrm{M}$ phase. This lag might indicate that, while repairing the MMC-induced DNA damage, the cells postpone the resolution of the G2 checkpoint. This arrest is shorter in normal cells given that they repair in a more efficient way thus having a more prominent contribution to the mitotic index when compared to FA cells. The highest percentage of MPM2+ cells of MMC treated normal cells might indicate a sharp delivery of previously G2 arrested cells, contrary to a smooth delivery of untreated normal cells. 


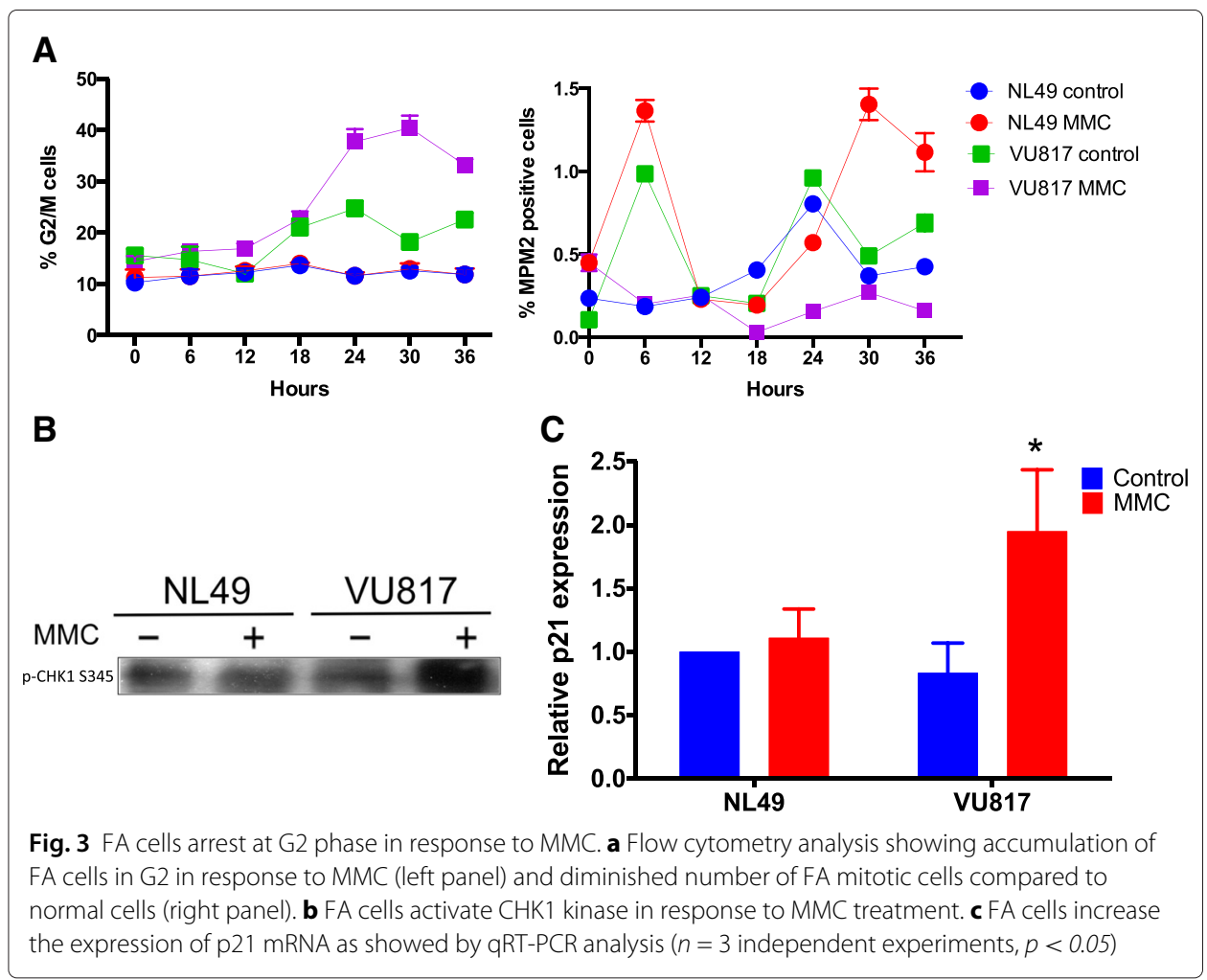

In FA-A cells treated with MMC we also observed increased CHK1 phosphorylation (Fig. 3b), a classical checkpoint activation marker, along with increased p21 mRNA expression (Fig. 3c). p21 is the main p53 target and is an important player for cell cycle arrest. The expression of this gene shows that the cell is committed to cell cycle arrest and its continuous expression is necessary to prevent cell division in cells that carry unrepaired chromosomes $[68,69]$. These experiments show that FA-A cells are able to activate mechanisms that halt cell cycle progression at the G2 phase upon DNA damage induction.

We then evaluated if FA-A and normal cells were able to divide despite unrepaired DNA damage. We quantified the cell division capacity after MMC treatment by performing a cytokinesis block assay with cytochalasin B (CB). Meanwhile, the DNA damage was evaluated by recording the frequency of micronuclei in multinucleated cells and the frequency of CAs in metaphase spreads.

$\mathrm{CB}$ experiments showed that treatment with MMC increased the proportion of mononucleated cells (cells that still do not divide due to G2 halt) (Fig. 4a upper panel), while the number of binucleated cells irrespective of the cell type (NL49 or VU817) or the addition or not of MMC remained the same (Fig. 4a middle panel). Remarkably, MMC treatment reduced significantly the number of tetranucleated FA cells (Fig. 4a bottom panel). On the other hand, the analysis of metaphase spreads showed that FA-A cells reached mitosis with a significantly higher frequency of CAs (Fig. 4b upper panel) than normal cells, and were able to divide despite unrepaired DNA damage, i.e. micronuclei (Fig. 4b bottom panel). These experiments show that FA-A cells first arrest in response to DNA damage but eventually reach cell division regardless of CA.

As suggested by our model, CHKREC activation could be relieving cell cycle arrest mediators, leading the cell to divide. To determine if the CHKREC components became 


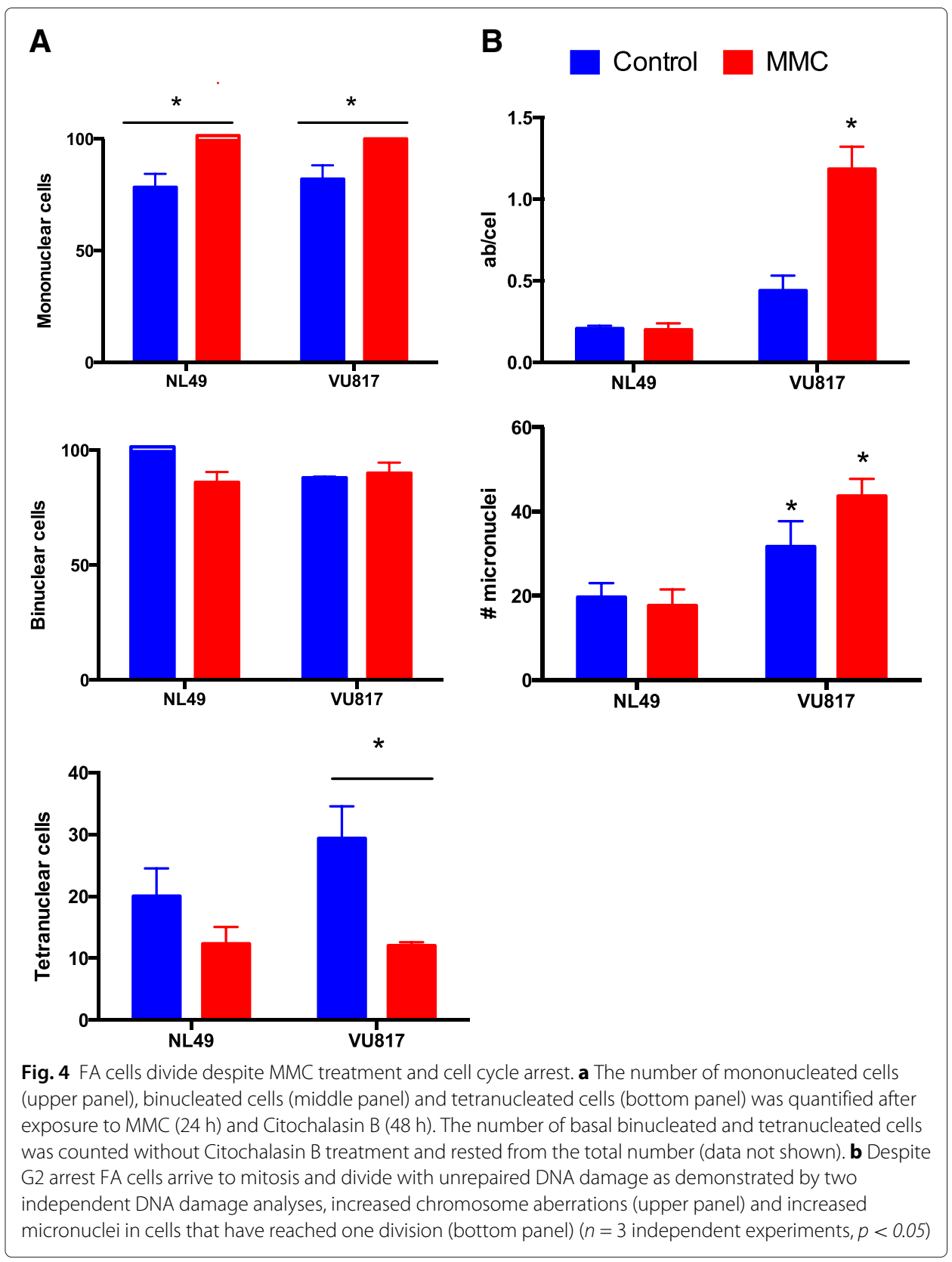

active in MMC treated FA cells, thus allowing their eventual division, we evaluated some molecular markers relevant for CHKREC and cell division. We analyzed by qRT-PCR the expression of the $\mathrm{G} 2$ transcriptional program, whose protein products are necessary for the G2/M transition; namely, Cyclin A2 (CCNA2, NM_001237.3), Cyclin B1 (CCNB1, NM_031966.3), WIP1 (PPM1D, NM_003620.3), FOXM1 (NM_001243088.1) and PLK1 (NM_005030.4) [16, 27, 70]. Our results show that the expression levels of these genes remain unaffected in FA-A cells, compared to wild type cells (Fig. 5a-e). Importantly, these genes are expressed in a cell cycle-dependent manner and are necessary for G2 phase completion [43], thus if they remain unchanged after MMC treatment, suggests 


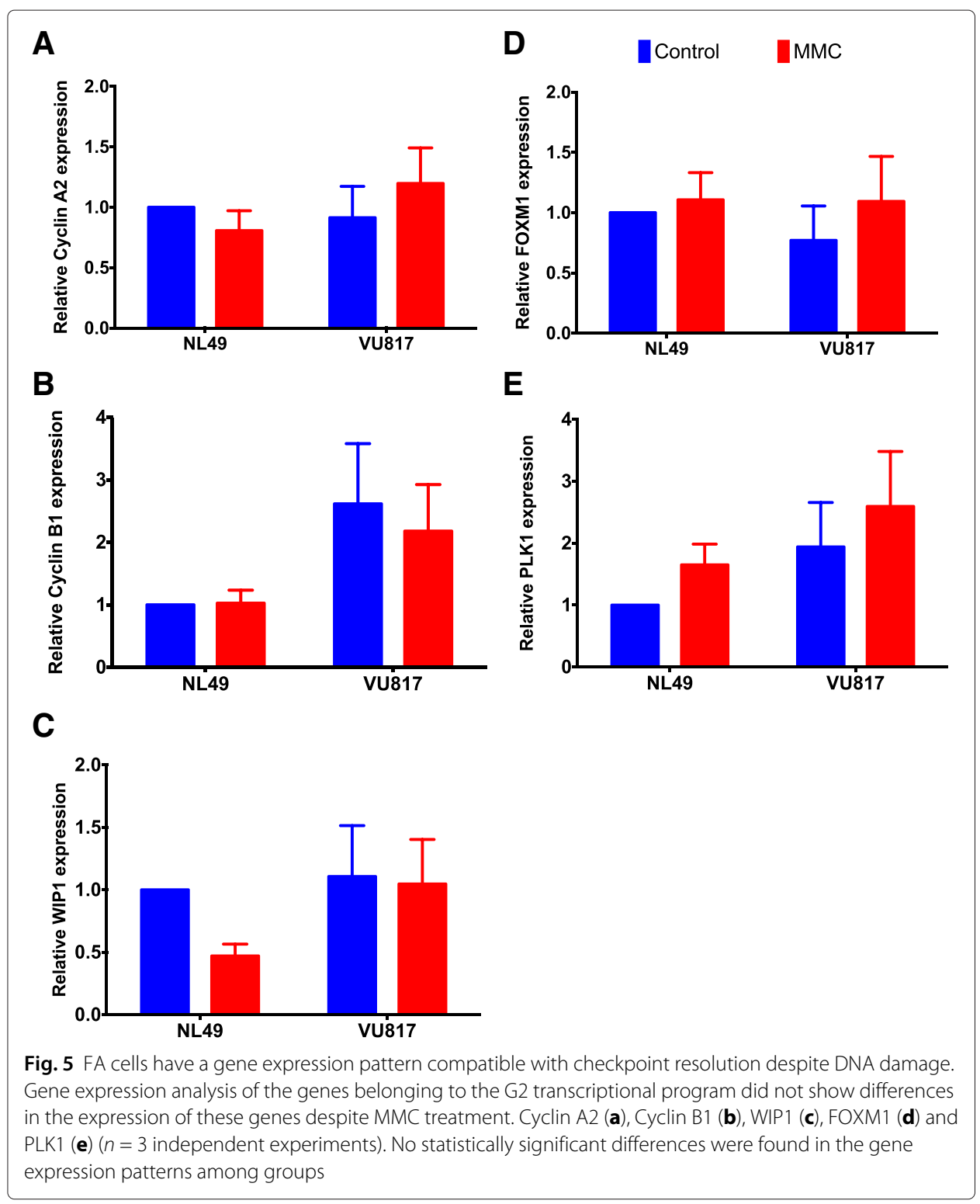

that this program remains poised for resolution of the G2 cell cycle blockage in FA cells, even with incomplete DNA repair.

Our BNM and these experimental results indicate that FA-A cells are able to block the cell cycle progression in G2 but eventually recover. Simulations with the BNM showed also that co-activation of G2 checkpoint and CHKREC components might occur in arrested FA cells, therefore, additional to CHK1, we evaluated other protein markers to asses key G2 checkpoint and CHKREC activation $24 \mathrm{~h}$ after MMC treatment. The G2 checkpoint markers included: WEE1, MYT1, p21 and $\gamma \mathrm{H} 2 \mathrm{AX}$; while CHKREC activation markers consisted of: WIP1, Aurora A, PLK1 and CDC25B.

We observed that CHK1 activity is increased after MMC treatment in FA-A cells (See Fig. 3b), but other checkpoint components, namely WEE1, p21 and $\gamma \mathrm{H} 2 \mathrm{AX}$ (Fig. 6a), have reduced levels. Remarkably, we also observed concomitant activation of CHKREC proteins PLK1, CDC25B and Aurora A (Fig. 6b) in damaged FA cells. Thus indicating 


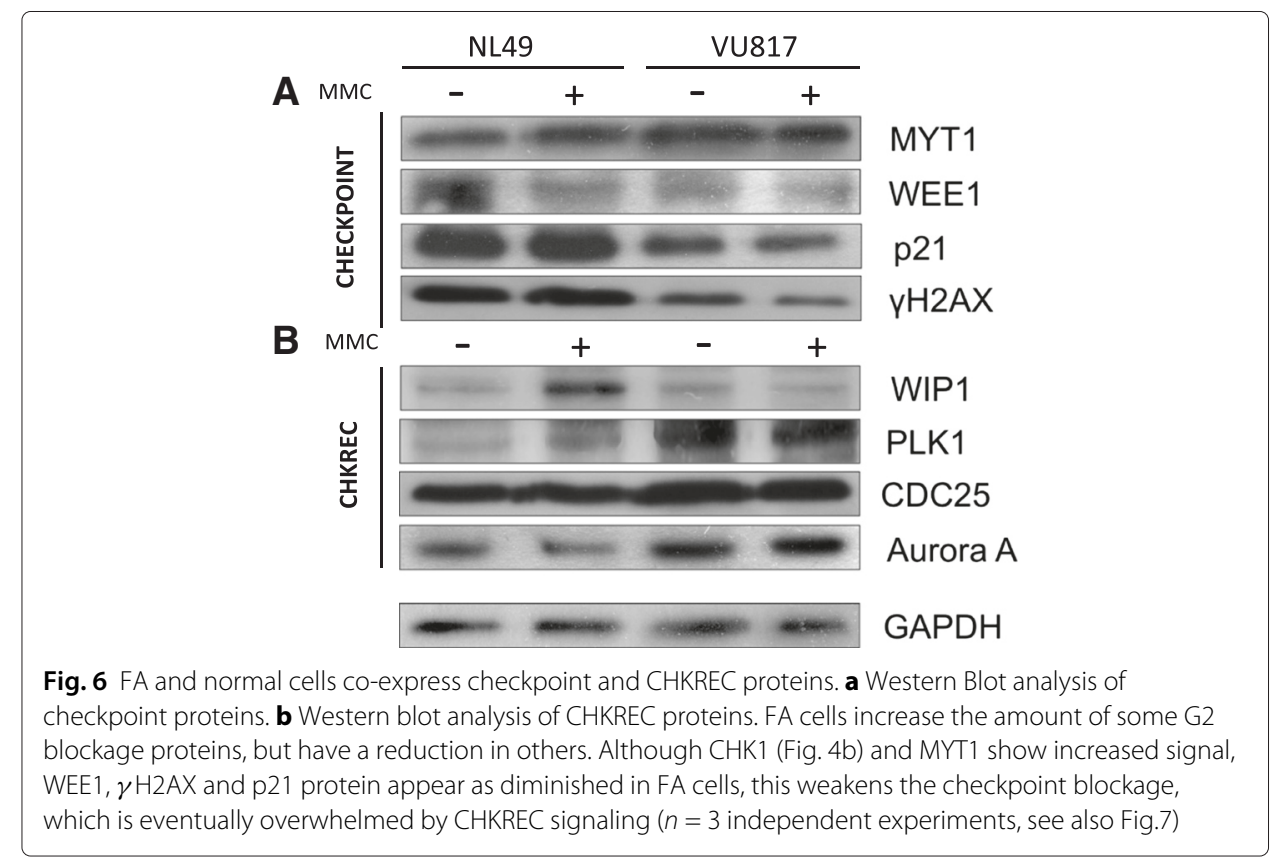

that despite a strong CHK1 signal that leads to cell cycle progression blockage, FA-A cells co-express the components that might dampen the DNA damage signaling and allow an eventual CHKREC despite an elevated amount of CA. In agreement, we observed in FA-A cells reduced levels of the histone $\gamma \mathrm{H} 2 \mathrm{AX}$, a DNA damage signaler and WIP1 phosphatase target. Notably, we also observed weakening of p21 protein signaling, which has also been correlated with CHKREC activation [71]. These results suggest that signaling of DSBs might be weakened at this time-point, triggering full CHKREC activation and cell division despite a strong CHK1 signaling and high levels of CAs (relative protein amount for all the markers can be seen in Fig. 7).

These experimental results show that the CHKREC is being activated in FA cells carrying CA to a similar extent as normal undamaged cells, this CHKREC induction might allow the escape of G2 with unrepaired DNA damage and cell division. The correlation between the nodes of the network and the experiments performed can be seen in Table 3 .

\section{Discussion}

Several methods are used to model and analyze biological systems [72-74]. These methods analyze the topology of the network or the kinetics of the system specifying the flux of information through a continuous model or a logical model [74].

Continuous models represent the temporal dynamics of biochemical processes with considerable detail, but are highly dependent on the values of free parameters (initial protein concentrations and rate constants), whose estimation might be challenging as networks get larger [73, 75]. Logical models rely on qualitative knowledge [72]. Logical BNM are the minimal computational model necessary to obtain a meaningful idea about the dynamics of a regulatory network and are useful when detailed enzymatic information is missing $[75,76]$. Many molecular regulatory systems show binary behaviors or act like bistable switches [77], thus the binary or discrete representation of BNM can adjusts to them and predict sequence patterns of proteins and gene activities with less 


\section{A}

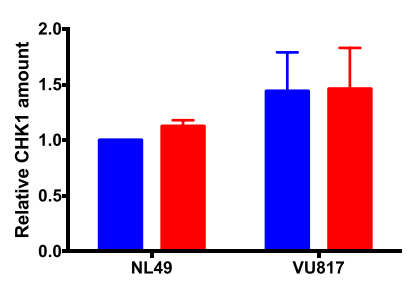

C

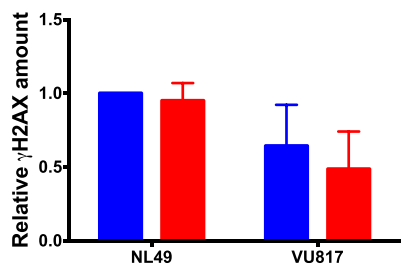

E

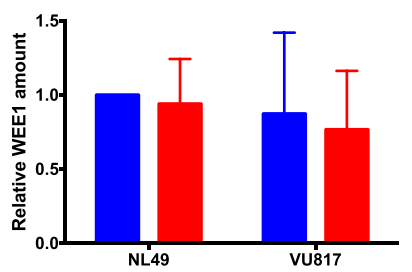

$\mathbf{F}$

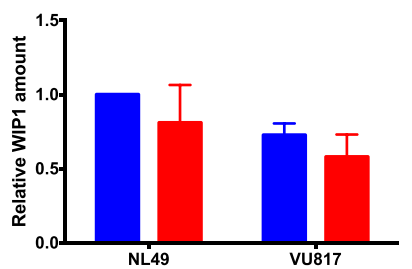

H

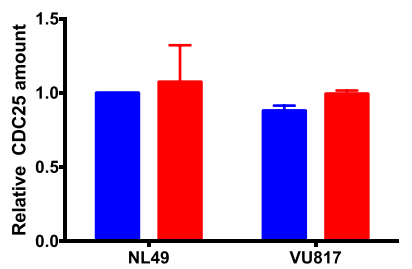

B

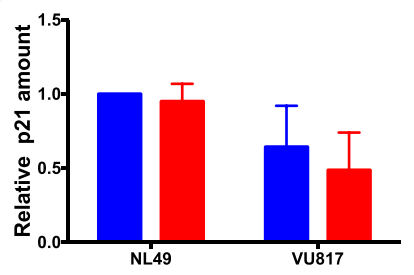

D

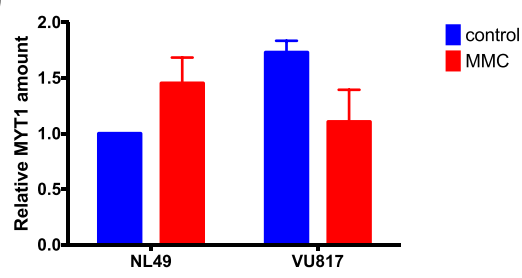

control

MMC

control
MMC

\section{政}

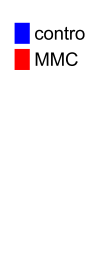

control
MMC$$
\text { . }
$$

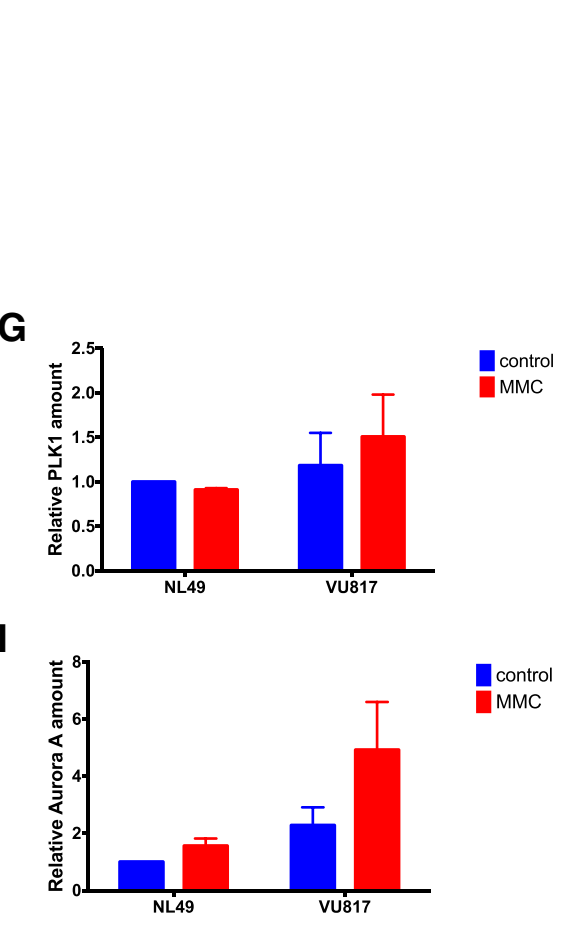

Fig. 7 Western Blot densitometry analysis. Checkpoint proteins (a-e) and CHKREC proteins $(\mathbf{f}-\mathbf{i}) .(n=3$ independent experiments). No statistically significant differences were found in the protein expression patterns among groups

parameters than a continuous model. Although BNM have been used for modeling several systems [32-37], they might not be appropriate if the system has continuous values or if knowledge on the network architecture is lacking [75].

We have developed a binary BNM that recapitulates in a simple manner the response to ICLs mediated by the FA/BRCA pathway [78]. Given that the different components of the network might remain unchanged, up-regulated or down-regulated instead of binary, an additional representation of the FA/BRCA network as a discrete ternary logical network might be also feasible [79], however a binary BNM resulted optimal given that our system presents gene expression showing a pattern of binary states (over-expressed, 
Table 3 Correlation between experimental validations and nodes in the FA/BRCA BNM

\begin{tabular}{|c|c|c|c|c|}
\hline Process & $\begin{array}{l}\text { Nodes in the } \\
\text { FA/BRCA BNM }\end{array}$ & $\begin{array}{l}\text { Experimental markers } \\
\text { used in this study }\end{array}$ & $\begin{array}{l}\text { Validated role } \\
\text { in the BNM }\end{array}$ & References \\
\hline $\begin{array}{l}\text { DNA damage } \\
\text { induction }\end{array}$ & $\mathrm{ICL}$ & MMC & $\begin{array}{l}\text { FA cells are } \\
\text { hypersensitive } \\
\text { to ICL inducing } \\
\text { agents }\end{array}$ & {$[21,25,26]$} \\
\hline $\begin{array}{l}\text { Upstream } \\
\text { FA/BRCA } \\
\text { pathway }\end{array}$ & $\begin{array}{l}\text { FAcore } \\
\text { FANCD21 } \\
\text { NUC1 } \\
\text { NUC2 }\end{array}$ & Non-evaluated & $\begin{array}{l}\mathrm{ICL} \text { recognition } \\
\text { proteins }\end{array}$ & {$[14,16,17]$} \\
\hline $\begin{array}{l}\text { DNA repair } \\
\text { intermediaries }\end{array}$ & $\begin{array}{l}\text { ADD } \\
\text { DSB }\end{array}$ & $\begin{array}{l}\gamma \mathrm{H} 2 \mathrm{AX}, \\
\mathrm{CA} \text { in metaphase } \\
\text { spreads }\end{array}$ & $\begin{array}{l}\text { ICLs are unhooked } \\
\text { by FA core-recruited } \\
\text { DNA-endonucleases } \\
\text { that generate a DSB } \\
\text { and an ADD }\end{array}$ & {$[13,21]$} \\
\hline $\begin{array}{l}\text { Downstream } \\
\text { FA/BRCA } \\
\text { pathway }\end{array}$ & $\begin{array}{l}\text { TLS } \\
\text { FAHRR }\end{array}$ & Non-evaluated & $\begin{array}{l}\text { The ADD and DSB } \\
\text { are repaired by TLS } \\
\text { and FA-dependent } \\
\text { downstream homologous } \\
\text { recombination repair, } \\
\text { respectively. FA cells } \\
\text { accumulate DSBs }\end{array}$ & {$[14,15,18,54]$} \\
\hline $\begin{array}{l}\text { Alternative } \\
\text { DNA repair } \\
\text { pathways }\end{array}$ & $\begin{array}{l}\text { HRR2 } \\
\text { NHEJ }\end{array}$ & Non-evaluated & $\begin{array}{l}\text { FA cells use } \\
\text { alternative DNA } \\
\text { repair pathways, } \\
\text { mainly NHEJ } \\
\text { HRR2 is a } \\
\text { criptic repair choice }\end{array}$ & {$[49,56]$} \\
\hline Checkpoint & $\begin{array}{l}\text { ATR } \\
\text { ATM } \\
\text { p53 }\end{array}$ & $\begin{array}{l}\text { Cell cycle arrest } \\
\text { in G2, pCHK1-S341, } \\
\text { p21 gene expression, } \\
\text { MYT1, WEE1, p21 } \\
\text { proteins }\end{array}$ & $\begin{array}{l}\text { Upon DNA damage } \\
\text { normal and FA } \\
\text { cells activate } \\
\text { the G2/M checkpoint }\end{array}$ & {$[27,28,31]$} \\
\hline $\begin{array}{l}\text { Checkpoint } \\
\text { recovery }\end{array}$ & CHKREC & $\begin{array}{l}\text { MPM2 mitotic index, } \\
\text { cytokinesis block assay, } \\
\text { G2/M transcriptional } \\
\text { program, WIP1, PLK1, } \\
\text { CDC25, Aurora A } \\
\text { proteins }\end{array}$ & $\begin{array}{l}\text { The checkpoint } \\
\text { is inactivated by } \\
\text { CHKREC after } \\
\text { DNA repair } \\
\text { FA cells seem to have } \\
\text { a lower threshold for } \\
\text { CHKREC activation } \\
\text { compared to normal cells }\end{array}$ & {$[83,84]$ and this work } \\
\hline
\end{tabular}

under-expressed) or protein concentrations that can reach a saturation regime (full activation) or remain in small concentrations (inactive). In addition the change to a ternary system would increase the possible states of the system from 32,768 to 14,348,907 states, thus augmenting the computational work.

Our modeling of the FA/BRCA regulatory network has led to the observation that CHKREC is a mechanism conferring stability to this system in wild type and FA cells ([38] and this work). CHKREC is fully activated once the G2/M checkpoint has been satisfied 
leading to the division of the cell [42]. CHKREC is mainly composed of phosphatases, such as WIP1, that inactivate the G2 checkpoint and protein-kinases that release the cell cycle blockage, such as Aurora A and PLK1 $[41,80]$. Notably, the negative circuits mediated by CHKREC seem to be a central part of the control system of the FA/BRCA network: they are activated when the system induces the expression of its own inhibitors, and are necessary to attenuate the stimulatory signals arising from DNA damage (Fig. 1 and Fig. 2).

When simulating mutants, we noticed that CHKREC function inactivates the checkpoint in FA core mutants despite unrepaired DNA damage, thus resolving the G2/M checkpoint arrest and allowing cell division. Therefore we should notice elevated/unchanged levels in the expression, quantity or activity of CHKREC components in FA cells with damaged DNA compared to undamaged normal cells, indicating that FA cells conserve checkpoint resolution capacity and are poised for cell division when the DNA damage checkpoint response ceases. To test the function of the CHKREC node, we experimentally evaluated the cell division capacity as well as checkpoint/CHKREC activation in FA-A lymphoblasts after induction of DNA damage with MMC.

We evaluated the G2 blockage and found accumulation of FA-A cells into the G2 phase compartment after induction of DNA damage (Fig. 3a left panel) and a reduced number of FA-A mitotic cells in comparison to normal cells after MMC exposition (Fig. 3a right panel). We also detected high CHK1 phosphorylation levels (Fig. 3b) as well as high p21 gene expression (Fig. 3c) in FA-A cells. CHK1 is a key protein kinase that transduces the DNA damage signaling, and p21 is a direct p53 transcription target, therefore an increase in p21 activation is the result of p53-increased activity, thus demonstrating that FA cells achieve a correct activation of the checkpoint that blocks the G2/M transition $[27,28] . \mathrm{p} 21$ is a negative regulator of Cyclin $\mathrm{B} / \mathrm{CDK} 1$ complex and is necessary to avoid the G2/M transition in presence of DNA damage [81]. Thus, CHK1 phosphorylation and p21 expression augment when a cell is exposed to DNA damaging agents and would be expected to drop-off once a cell has repaired the DNA damage [82].

When we evaluated the cell division capacity in a CB block assay, we did not observe differences in the frequency of binucleated cells between normal and FA-A cells (Fig. 4 middle panel), although MMC limited tetranucleated cells production in both cell types (Fig. 4c bottom panel). These results show that, under these experimental conditions, both FA-A and normal cells divide to a similar extent after induction of DNA damage by MMC.

The capability of FA cells to divide with unrepaired DNA damage was evaluated by quantifying the frequency of DNA damage induced by $M M C$ in cells committed to divide by scoring CAs in metaphase spreads, as well as in cells that have already performed cell division by quantifying the micronuclei observed in binucleated and tetranucleated cells. Our results showed, in both assays, that FA-A cells exposed to MMC carry significant DNA damage during mitosis and, nonetheless divide (Fig. 4b).

Our BNM allowed us to propose that CHKREC function in FA cells might ignore in a certain level the presence of unrepaired DNA damage and could be responsible for their division, therefore we expected that normal and FA-A cells would have similar activation levels of the CHKREC components. To test this possibility, we measured the expression of the G2 transcriptional program genes that promote CDK activity and 
progression into mitosis, namely WIP1, Cyclin A2, Cyclin B1, PLK1, CDC25 and FOXM1 [43] (Fig. 5a-e) and evaluated the activation of some of the proteins involved in checkpoint and CHKREC (Fig. 6). In the first assay we observed that the expression of the genes that enable CHKREC and cell division are similar in normal/undamaged cells and damaged FA cells, even when FA cells carry a higher number of CAs. In addition, we observed co-expression of checkpoint and CHKREC proteins in FA cells treated with MMC (Fig. 6 and 7), indicating that damaged FA cells are poised for an eventual cell division despite DNA damage (Fig. 8).

Checkpoint activation, cell cycle arrest and DNA repair require a great number of protein posttranslational modifications for their establishment. Dedicated enzymes that remove these modifications or degrade modified proteins allow checkpoint silencing and recovery [84]. WIP1 phosphatase and PLK1 kinase emerge as the coordinators of checkpoint silencing and recovery, respectively, however if there exist a certain order in their activation remains elusive. In general terms for cell division, Cyclin B levels must gradually increase, while CDC25 phosphatase should remove any inhibitory phosphorylation of CDK1, thus promoting Cyclin B/CDK1 complex formation and mitotic entry. However, after induction of DNA damage, the G2 checkpoint inhibits CDK1 activity through p21, whilst WEE1 and MYT1 kinases degrade CDC25, avoiding mitotic entry [42, 70, 80].

WIP1 phosphatase dephosphorylates ATM, p53, CHK1, CHK2, $\gamma \mathrm{H} 2 \mathrm{AX}$ and the $\mathrm{p}(\mathrm{S} / \mathrm{T}) \mathrm{Q}$ motif originally modified by ATM and ATR $[85,86]$. During CHKREC, AuroraA kinase activates PLK1, which in turn targets WEE1 for proteasomal degradation and releases CDK1 from blockage [42, 87-89], in addition PLK1 interferes with CHK1, CHK2 and p53 stability, thus it also has an active role turning-off the DNA damage checkpoint [40].

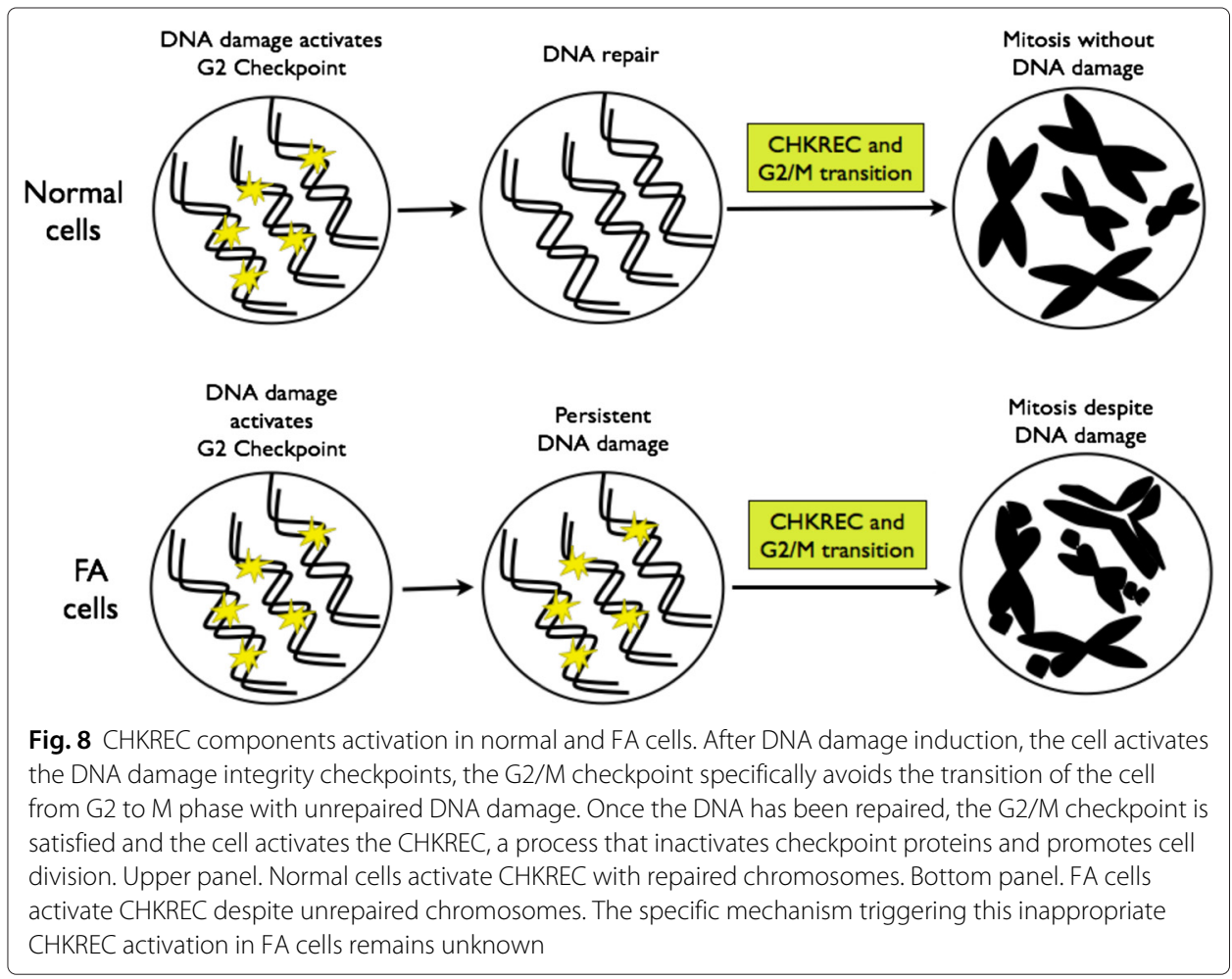


In Fig. 6b we observe that the concentration of WIP1 is increased in normal cells and reduced in FA cells; on the contrary PLK1 is reduced in normal cell and increased in FA cells. Interestingly, PLK1 activity is redundant in unperturbed mitotic entry whereas it becomes essential in CHKREC after DNA damage [88, 89], consistently it is activated in our experiments in damaged FA-A cells. As FA cells carry spontaneous unrepaired DNA damage, this implies that their transition through G2 is always perturbed to a certain extent, thus PLK1 should become essential for FA cells survival. Given this, PLK1 over-activation must be involved in the adaptation of FA cells to DNA damage. Recent evidence shows that PLK1 activity is gradually increased during an ongoing DNA damage-induced cell cycle arrest and if the activity of the kinase exceeds beyond a certain level, the cell progresses to mitosis despite DNA damage persistance [83]. G2 checkpoint recovery might thus represent a checkpoint adaptation, where DNA damage triggers an arrest whose duration is not necessarily conditioned by DNA repair [84]. Regarding this, PLK1 might have a more critical role than WIP1 in the delivery of FA cells with unrepaired DNA damage from the G2 arrest, or WIP1 is acting before than the time-point that we are evaluating in this assays, hence we are not able to detect WIP1 protein (Fig. 6b). The distinction between both possible scenarios deserves further research.

A final aspect to be considered are the findings of Ceccaldi and coworkers [31], who described an attenuated G2/M checkpoint activity in adult FA individuals that, concomitantly to low CHK1 and p53 protein levels, allowed the escape of unrepaired DNA damage. Although they demonstrate that downregulation of the ATR-CHK1 axis is responsible for this phenotype, it remains elusive if this reduced checkpoint activity might be due to CHKREC over-activation or ectopic activity. In this study we set the basis to explore this possibility in FA individuals with an attenuated G2/M checkpoint and the general mechanism allowing G2/M resolution in non-attenuated FA individuals. Further, modeling the full interaction between the G2/M checkpoint and CHKREC, as well as a systematic inhibition of CHKREC components in FA cells, will shed light into the intricate interactions between these two processes.

Our results show that highly damaged FA-A cells preserve the capacity to divide after a cell cycle arrest induced by DNA damage, a result that is consistent with our BNM FA core null mutant simulations. Nonetheless, the definition of the specific trigger for cell division remains unknown. To our judgment, the CHKREC hypothesis became the most relevant hypothesis emerging from our BNM given that CHKREC promotion might enable cell survival and amelioration of blood cell counts in pancytopenic FA patients, however CHKREC overexpression might also lead to exhaustion of the hematopoietic stem cell compartment as well as selection of malignant clones. Therefore, the thorough study of this process becomes relevant for the understanding of hematopoiesis and carcinogenesis in a FA background.

\section{Conclusion}

In this study we propose through network modeling that CHKREC, a program necessary for cell division after DNA damage, becomes activated in FA core mutant cells with unrepaired DNA damage. We experimentally show that highly damaged FA-A cells have CHKREC expression levels similar to those observed in normal undamaged cells, thus FA-A cells might ignore the presence of broken chromosomes through this process. We 
observed that despite a prominent G2 arrest after MMC exposure, FA cells were able to activate the mechanisms that allow cell division (Fig. 8).

FA cells are prone to apoptosis due to their DNA repair defects, however a great quantity of them divide in spite of unrepaired DNA damage, thus allowing the survival of FA individuals. The study of the mechanisms that allow FA cells to survive may help to develop novel therapies designed to promote hematopoiesis, as well as to avoid the division of malignant clones in FA patients.

\section{Competing interests}

The authors declare that they have no competing interests.

\section{Authors' contributions}

$A R$, LM and SF conceived the project; AR, DS and EA developed the BNM; AR, LT, UJ, DS, BGT, EC and AMS performed experiments; $\mathrm{RO}$ and POW provided essential reagents; LM coordinated computational work; SF coordinated laboratory work. All authors read and approved the final manuscript.

\section{Acknowledgements}

Authors thank our colleagues at Dr. Frías' laboratory for insightful discussions and Anet Rivera Osorio for invaluable assistance with experiments. This work was supported in part by grants from Universidad Nacional Autónoma de México PAPIIT IN200514 and IA201713, and Instituto Nacional de Pediatría-SSA, Fondos Federales 043-12. AR received the 346717 scholarship from Consejo Nacional de Ciencia y Tecnología (CONACyT). We thank S Becerra and J Yañez from IBT UNAM for primer synthesis.

\footnotetext{
Author details

${ }^{1}$ Laboratorio de Citogenética, Departamento de Investigación en Genética Humana, Instituto Nacional de Pediatría, D.F., México. ${ }^{2}$ Programa de Doctorado en Ciencias Biomédicas, Universidad Nacional Autónoma de México, D.F., México. ${ }^{3}$ Instituto de Ecología, Universidad Nacional Autónoma de México, D.F., México. ${ }^{4}$ C3, Centro de Ciencias de la Complejidad, Universidad Nacional Autónoma de México, D.F., México. ${ }^{5}$ Current address: INRIA, Virtual Plants Project Team, UMR AGAP, Montpellier, France. ${ }^{6}$ Departamento de Ciencias de la Salud, Universidad Autónoma Metropolitana-Iztapalapa, D.F., México. ${ }^{7}$ Instituto de Investigaciones Biomédicas, Universidad Nacional Autónoma de México, D.F., México.
}

Received: 26 May 2015 Accepted: 12 August 2015

Published online: 18 September 2015

\section{References}

1. Surralles J, Jackson SP, Jasin M, Kastan MB, West SC, Joenje H. Molecular cross-talk among chromosome fragility syndromes. Genes Dev. 2004;18(12):1359-70.

2. Aurias A, Antoine JL, Assathiany R, Odievre M, Dutrillaux B. Radiation sensitivity of bloom's syndrome lymphocytes during $S$ and $G 2$ phases. Cancer Genet Cytogenet. 1985;16(2):131-6.

3. Krepinsky AB, Heddle JA, German J. Sensitivity of Bloom's syndrome lymphocytes to ethyl methanesulfonate. Hum Genet. 1979;50(2):151-6.

4. Taylor AMR. Unrepaired DNA strand breaks in irradiated ataxia telangiectasia lymphocytes suggested from cytogenetic observations. Mutat Res Fundam Mol Mech Mutagen. 1978;50(3):407-18

5. German J, Reginald A, David B. Chromosomal breakage in a rare and probably genetically determined syndrome of man. Science. 1965;148.3669:506-7.

6. German J, Sanz MM, Ciocci S, Ye TZ, Ellis NA. Syndrome causing mutations of the BLM gene in persons in the Bloom's Syndrome Registry. Hum Mutat. 2007;28(8):743-53.

7. Chaganti RSK, Schonberg S, German J. A manyfold increase in sister chromatid exchanges in Bloom's syndrome lymphocytes. Proc Natl Acad Sci. 1974;71(11):4508-12.

8. Tadjoedin MK, Fraser FC. Heredity of ataxia-telangiectasia (Louis-Bar syndrome). Am J Dis Child. 1965;110(1):64-8.

9. Concannon P, Gatti RA. Diversity of ATM gene mutations detected in patients with ataxia-telangiectasia. Hum Mutat. 1997;10(2):100

10. Kojis TL, Gatti RA Sparkes, RS. The cytogenetics of ataxia telangiectasia. Cancer Genet Cytogenets. 1991;56(2): $143-156$.

11. Oxford JM, Harnden DG, Parrington JM, Delhanty JD. Specific chromosome aberrations in ataxia telangiectasia. J Med Genet. 1975;12(3):251-62.

12. Lobitz S, Velleuer E. Guido Fanconi (1892-1979): a jack of all trades. Nat Rev Cancer. 2006:6(11):893-8.

13. de Winter J, Joenje H. The genetic and molecular basis of Fanconi anemia. Mutat Res. 2009;668:11-9.

14. Kee Y, D'Andrea AD. Expanded roles of the Fanconi anemia pathway in preserving genomic stability. Genes Dev. 2010;24:1680-94.

15. Vaz F, Hanenberg H, Schuster B. Mutation of the RAD51C gene in a fanconi anemia-like disorder. Nat Genet. 2010;42:406-9.

16. Kim Y, Lach F, Desetty R, et al. Mutations of the SLX4 gene in fanconi anemia. Nat Genet. 2011;43:142-6.

17. Bogliolo M, Schuster B, Stoepker C, et al. Mutations in ERCC4, encoding the DNA-repair endonuclease XPF cause Fanconi anemia. Am J Hum Genet. 2013:92:800-6. 
18. Greenberg RA, Sawyer SL, Tian L, et al. Biallelic mutations in BRCA1 cause a new Fanconi anemia subtype. Cancer discov.2014;CD-14.

19. Hira A, Yoshida K, Sato K, Okuno Y, Shiraishi Y, Chiba K, et al. Mutations in the Gene Encoding the E2 Conjugating Enzyme UBE2T Cause Fanconi Anemia. Am J Hum Genet. 2015;96(6):1001-7.

20. Schroeder TM, German J. Bloom's syndrome and Fanconi's anemia: demonstration of two distinctive patterns of chromosome disruption and rearrangement. Humangenetik. 1974;25(4):299-306.

21. Auerbach A. Fanconi anemia and its diagnosis. Mutat Res. 2009;668:4-10.

22. Amor-Guéret M. Bloom syndrome, genomic instability and cancer: the SOS-like hypothesis. Cancer Lett. 2006;236(1): $1-12$.

23. Soulier J. Fanconi anemia. Hematol Am Soc Hematol Educ Prog. 2011492-7.

24. Tulpule A, Lensch MW, Miller J, et al. Knockdown of Fanconi anemia genes in human embryonic stem cells reveals early developmental defects in the hematopoietic lineage. Blood. 2011;115(17):3453-62.

25. Langevin F, Crossan GP, Rosado IV, et al. Fancd2 counteracts the toxic effects of naturally produced aldehydes in mice. Nature. 2011;475:53-8.

26. Rosado IV, Langevin F, Crossan GP, et al. Formaldehyde catabolism is essential in cells deficient for the Fanconi anemia DNA-repair pathway. Nat Struct Mol Biol. 2011;18:1432-4.

27. Ceccaldi R, Parmar K, Mouly E, et al. Bone marrow failure in Fanconi anemia is triggered by an exacerbated p53/p21 DNA damage response that impairs hematopoietic stem and progenitor cells. Cell Stem Cell. 2012;11:36-49.

28. Heinrich $M$, Hoatlin ME, Zigler AJ, et al. DNA cross-linker-induced G2/M arrest in group C Fanconi anemia lymphoblasts reflects normal checkpoint function. Blood. 1998;91:275-87.

29. Freie B, Ciccone S, Li X, et al. A role for the Fanconi anemia C protein in maintaining the DNA damage-induced G2 checkpoint. J Biol Chem. 2004;279:50986-93.

30. Neveling K, Endt D, Hoehn H, et al. Genotype-phenotype correlations in Fanconi anemia. Mutat Res. 2009;668:73-91.

31. Ceccaldi R, Briot D, Larghero J, et al. Spontaneous abrogation of the G2 DNA damage checkpoint has clinical benefits but promotes leukemogenesis in Fanconi anemia patients. J Clin Invest. 2011;121:184-94.

32. Faure A, Naldi A, Chaouiya C, et al. Dynamical analysis of a generic boolean model for the control of the mammalian cell cycle. Bioinformatics. 2006;22:e124-131.

33. Mendoza L. A network model for the control of the differentiation process in Th cells. Biosystems. 2006;84:101-14.

34. Zhang R, Shah MV, Yang J, et al. Network model of survival signaling in large granular lymphocyte leukemia. Proc Natl Acad Sci USA. 2009;105:16308-13.

35. Chaves M, Albert R, Sontag E. Robustness and fragility of Boolean models for genetic regulatory networks. J Theor Biol. 2005;235:431-49.

36. Christensen C, Thakar J, Albert R. Systems-level insights into cellular regulation: inferring, analyzing, and modelling intracellular networks. IET Syst Biol. 2007;1:61-77.

37. Wu M, Yang X, Chan C. A dynamic analysis of IRS-PKR signaling in liver cells: a discrete modeling approach. PLoS One. 2009;4(12):e8040.

38. Rodriguez A, Sosa D, Torres $L$, et al. A Boolean network model of the FA/BRCA pathway. Bioinformatics. 2012;28: $858-66$.

39. van Vugt $M$, Yaffe $M$, et al. Cell cycle re-entry mechanisms after DNA damage checkpoints: Giving it some gas to shut off the breaks. Cell Cycle. 2010;11:2097-101.

40. van Vugt MA, Gardino AK, Linding R, et al. A mitotic phosphorylation feedback network connects Cdk1, PIk1, 53BP1 and Chk2 to inactivate the G2/M DNA damage checkpoint. PLoS Biol. 2010;8:e1000287.

41. Halim V, Alvarez-Fernandez M, Xu YJ, et al. omparative phosphoproteomic analysis of checkpoint recovery identifies new regulators of the DNA damage response. Sci Signal. 2013;6:rs9.

42. Medema RH, Macurek L. Checkpoint recovery in cells: how a molecular understanding can help in the fight against cancer. F1000 Biol Rep. 2011;3.

43. Álvarez-Fernández M, Medema RH, Lindqvist A. Transcriptional regulation underlying recovery from a DNA damage-induced arrest. Transcription. 2010;1:32-5.

44. Meetei AR, et al. A Human Orthologue of Archaeal DNA Repair Protein Hef is Defective in Fanconi Anemia Complementation Group. M Nat Genet. 2005;37:958-63.

45. Kee Y, et al. Regulated degradation of FANCM in the Fanconi anemia pathway during mitosis. Genes Dev. 2009;23: $555-60$.

46. Wang XZ, et al. Chk1-Mediated Phosphorylation of FANCE Is Required for the Fanconi Anemia/BRCA Pathway. Mol Cell Biol. 2007;27:3098-108.

47. Smogorzewska A, et al. Identification of the Fanconi anemia (FANC) I protein, a monoubiquitinated FANCD2 paralog required for crosslink repair. Cell. 2007;129:289-301.

48. Bogliolo M, et al. Histone H2AX and Fanconi anemia FANCD2 function in the same pathway to maintain chromosome stability. EMBO J. 2007;26:1340-51.

49. Pace P, et al. Ku70 Corrupts DNA Repair in the Absence of the Fanconi Anemia Pathway. Science. 2010;329:219-23.

50. Bhagwat N, et al. XPF-ERCC1 Participates in the Fanconi Anemia Pathway of Cross-Link Repair. Mol Cell Biol. 2009;29: 6427-37.

51. Hanada $\mathrm{K}$, et al. The structure-specific endonuclease Mus81/Eme1 promotes conversion of interstrand DNA crosslinks into double-strands breaks. EMBO J. 2006;25:492125-4932.

52. Lieber MR. The Mechanism of Double-Strand DNA Break Repair by the Nonhomologous DNA End-Joining Pathway. Annu Rev Biochem. 2010;79:181-211.

53. Chang DJ, Cimprich KA. DNA damage tolerance: when it's OK to make mistakes. Nature Chem Biol. 2009;5:82-90.

54. Mirchandani KD, et al. The Fanconi anemia core complex is required for efficient point mutagenesis and Rev1 foci assembly. DNA Repair. 2008;7:902-11.

55. Kass EM, Jasin M. Collaboration and competition between DNA double-strand break repair pathways. FEBS Letters. 2010;584:3703-8. 
56. Adamo A, et al. Preventing Non-homologous End-Joining suppresses DNA repair defects of Fanconi Anemia. Mol Cell. 2010;39:25-35.

57. Yaneva M, et al. Interaction of DNA-dependent protein kinase with DNA and with KU: biochemical and atomic-force microscopy studies. EMBO J. 1997;16:5098-112.

58. Cimprich KA, Cortez D. ATR: an essential regulator of genome integrity. Nat Rev Mol Cell Biol. 2008;9:616-127.

59. Collis SJ, et al. FANCM and FAAP24 function in ATR- Mediated Checkpoint Signaling Independently of the Fanconi Anemia Core Complex. Mol Cel. 2008;32:313-24.

60. Jazayeri A, et al. ATM- and cell cycle-dependent regulation of ATR in response to DNA double-strand breaks. Nature Cell Biol. 2006;8:37-45.

61. Stiff T, et al. ATR-dependent phosphorylation and activation of ATM in response to UV treatment or replication fork stalling. EMBO J. 2006;25:5775-82.

62. Lavin MF. ATM and the Mre11 complex combine to recognize and signal DNA double-strand breaks. Oncogene. 2008:26:7749-58.

63. Lee J, et al. The Rad9-Hus1-Rad1 Checkpoint Clamp regulates interaction of TopBP1 with ATR. J Biol Chem. 2007;282: 28036-44.

64. Shieh S, et al. The human homologs of checkpoint kinases Chk1 and Cds1 (Chk2) phosphorylate p53 at multiple DNA damage-inducible sites. Genes Dev. 2000;14:289-300.

65. Bassermann F, Pagano M. Dissecting the role of ubiquitylation in the DNA damage response checkpoint in G2. Cell Death Differ. 2010;17:78-85.

66. Mussel C, Hopfensitz M, Kestler HA. BoolNet-an R package for generation, reconstruction and analysis of Boolean networks. Bioinformatics. 2010;26:1378-80

67. Fenech M, Morley AA. Measurement of micronuclei in lymphocytes. Mutat Res. 1985;147:29-36

68. Zhou B, Elledge SJ. The DNA damage response: putting checkpoints in perspective. Nature. 2000;408:433-9.

69. Khanna KK, Jackson SP. DNA double-strand breaks: signaling, repair and the cancer connection. Nat Genet. 2001;27: 247-54.

70. Bloom J, Cross FR. Multiple levels of cyclin specificity in cell-cycle control. Nat Rev Mol Cell Biol. 2007:8:149-60

71. Krenning L, Feringa FM, Shaltiel IA, et al. Transient activation of $\mathrm{p} 53$ in $\mathrm{G} 2$ phase is sufficient to induce senescence. Molecular Cell. 2014;55:59-72.

72. Karlebach G, Shamir R. Modelling and analysis of gene regulatory networks. Nat Rev Mol Cell Biol. 2008;9(10):770-80.

73. Morris MK, Saez-Rodriguez J, Sorger PK, Lauffenburger DA. Logic-based models for the analysis of cell signaling networks. Biochemistry. 2010;49(15):3216-24.

74. Tenazinha N, Vinga S. A survey on methods for modeling and analyzing integrated biological networks. IEEE/ACM Trans Comput Biol Bioinforma (TCBB). 2011;8(4):943-58.

75. Bornholdt S. Boolean network models of cellular regulation: prospects and limitations. J R Soc Interface 5. 2008;1: S85-S94.

76. Lazebnik Y. Can a biologist fix a radio? —or, what I learned while studying apoptosis. Biochemistry (Moscow). 2004;69(12):1403-6

77. Tyson JJ, Chen KC, Novak B. Sniffers, buzzers, toggles and blinkers: dynamics of regulatory and signaling pathways in the cell. Curr Opin Cell Biol. 2003;15(2):221-31.

78. Wang AT, Smogorzewska A. SnapShot: Fanconi anemia and associated proteins. Cell. 2015;160(1):354.

79. Fritsch $P$, Craddock TJA, del Rosario RM, Rice MA, Smylie A, Folcik VA, et al. Succumbing to the laws of attraction: Exploring the sometimes pathogenic versatility of discrete immune logic. Syst Biomed. 2013;1(3):179-94.

80. Peng A. Working hard for recovery: mitotic kinases in the DNA damage checkpoint. Cell Biosci. 2013;3:20.

81. Amador V, Ge S, Santamaría PG, et al. APC ${ }^{\mathrm{CDC} 20}$ controls the ubiquitin-mediated degradation of p21 in prometaphase. Mol Cell. 2007;3:462-73.

82. Mailand N, Bekker-Jensen S, Bartek J, et al. Destruction of Claspin by SCF ${ }^{\text {TrCP }}$ restrains Chk1 activation and facilitates recovery from genotoxic stress. Mol Cell. 2006;23:307-18.

83. Liang H, Esposito A, De S, Ber S, Collin P, Surana U, et al. Homeostatic control of polo-like kinase-1 engenders non-genetic heterogeneity in G2 checkpoint fidelity and timing. Nat Commun. 2014;5.

84. Shaltiel IA, Krenning L, Bruinsma W, Medema RH. The same, only different-DNA damage checkpoints and their reversal throughout the cell cycle. J Cell Sci. 2015;128:607-20.

85. Lindqvist A, de Bruijn M, Macurek L, et al. Wip1 confers $\mathrm{G} 2$ checkpoint recovery competence by counteracting p53 dependent transcriptional repression. EMBO J. 2009;20:3196-206.

86. Shaltiel IA, Aprelia M, Saurin AT, et al. Distinct phosphatases antagonize the p53 response in different phases of the cell cycle. Proc Natl Acad Sci USA. 2014;20:7313-8.

87. Seki A, Coppinger J, Jang C, et al. Bora and the kinase Aurora A cooperatively activate the kinase Plk1 and control mitotic entry. Science. 2008;320:1655-8.

88. Macurek L, Lindqvist A, Lim D, et al. Polo-like kinase-1 is activated by aurora A to promote checkpoint recovery. Nature. 2008:455:119-23.

89. van Vugt MA, Brás A, Medema RH. Polo-like kinase-1 controls recovery from a G2 DNA damage-induced arrest in mammalian cells. Mol Cell. 2004;15(5):799-811. 